\title{
Ventricular fibrillation in the course of Prinzmetal's angina pectoris Report of two cases
}

\author{
G. F. Levi and C. Proto \\ From Spedali Civili di Brescia, Medicina Generale IVa Divisione-Gussago, Brescia, Italy
}

The presentation of 2 cases of ventricular fibrillation in a group of 7 patients with Prinzmetal's angina suggests that severe arrhythmia may be common with this type of coronary insufficiency. Clinically, a sequence of spontaneous anginal pain, palpitation, and syncope is suggestive of the syndrome; the electrocardiogram characteristically shows a monophasic ST-T wave which persists only for the duration of the episode.

Patients suspected of having this type of angina should be admitted to hospital and monitored in a coronary care unit, pending decision on an aortocoronary bypass operation.

In the two cases observed by us, treatment with practolol (400 mg daily) was effective in abating both the anginal episodes and the ventricular arrhythmia.

The introduction of continuous electrocardiographic monitoring has afforded the demonstration of episodes of acute coronary insufficiency far more often than was previously possible.

Some of these episodes differ from the normal electrocardiographic picture in that they show a characteristic alteration of ST and T amounting to a single, monophasic wave; these are associated with a 'variant form of angina pectoris' often called Prinzmetal's angina (Guazzi et al., 1970; Meriel et al., 1966; Peretz, 196I ; Prinzmetal et al., 1959). In most patients of this description, coronary arteriography reveals a single, circumscribed obstruction in one of the main coronary branches (Silverman and Flamm, 197I).

Clinically, Prinzmetal's angina occurs in the form of anginal episodes appearing spontaneously, not triggered by physical exertion, usually of short duration, and associated with profuse sweating, severe distress, and sometimes syncope (Dorra et al., I968).

According to Raynaud et al. (1969), 50 per cent of the patients with variant angina also present with severe alterations of cardiac rhythm; and a sequence of spontaneous pain, palpitation, and syncope must be regarded as suggestive of Prinzmetal's angina.

In our own experience, continuous monitoring of a group of 7 patients with Prinzmetal's angina has Received 30 October 1972. enabled two episodes of ventricular fibrillation to be detected, which were successfully treated by electrical defibrillation.

\section{Case reports}

\section{Case I}

A 47-year-old man was in hospital, and gave a history of anginal episodes of 3 months' duration, sometimes after exertion and sometimes at rest, becoming more frequent in the last few weeks, particularly on awakening, lasting 3 or 4 minutes each, and accompanied by sweating and prostration. On admission the patient was free of pain; cardiac auscultation was noncontributory; heart rate was $70 / \mathrm{min}$; arterial blood pressure was $170 / 95 \mathrm{mmHg}$; peripheral pulses were normal; the electrocardiogram was unremarkable.

Serum lipoprotein electrophoresis revealed a moderate increase of the pre- $\beta$ fraction. All other blood chemistry findings were normal.

The electrocardiogram of an anginal episode on the second hospital day revealed a giant monophasic wave in the right praecordial leads, disappearing in 2 to 3 minutes. On the fourth day the patient (now transferred to our cardiac monitoring unit) suffered an episode of severe coronary pain radiating to the chest and jaws, associated with profuse sweating. The electrocardiogram showed a monophasic wave in I, VL, with a mirror image in II, III, and VF. While his cardiogram was being recorded, the patient developed ventricular fibrillation and fainted. A first attempt at defibrillation with roo Joules was unsuccessful; the second attempt, 
with 300 Joules, resolved the arrhythmia. Despite lignocaine perfusion and anticoagulant therapy, the patient suffered several further episodes of anginal pain in the next few days, always of the Prinzmetal type and with bouts of ventricular extrasystoles which yielded to treatment only with practolol at a dose of $400 \mathrm{mg}$ daily. Coronary arteriography, carried out two months later at the Ospedale Policlinico San Matteo, University of Pavia, revealed a proximally located, circumscribed stenosis of the anterior descending coronary artery.

On 2 December 197 I the patient underwent surgery (aortocoronary venous bypass) in the Department of Surgery, University of Pavia. His postoperative course was excellent, with complete freedom from anginal pain. At the time of writing this paper, the patient continues to be asymptomatic and is able to undertake a fair amount of physical activity.

\section{Case 2}

A 65-year-old man was admitted to hospital as an emergency because of prolonged anginal episodes. The patient gave a two-month history of frequent praecordial pain, sometimes at rest, each episode lasting 4 or 5 minutes and being associated with sweating, severe distress, and momentary fainting. Clinical examination of the cardiovascular system, as well as electrocardiograms, were essentially noncontributory.
One hour after admission to the heart monitoring unit, the patient had a further episode of chest pain. While the praecordial leads were being recorded, he developed ventricular fibrillation with loss of consciousness (Fig. I); an electric shock of 250 Joules restored sinus rhythm.

On his second and fourth hospital day, the patient developed repeated bouts of anginal pain, each lasting 2 to 3 minutes, and associated with the appearance of a monophasic wave in the praecordial leads. In spite of lignocaine infusions, both ventricular extrasystole and atrial fibrillation (Fig. 2) occurred repeatedly during the anginal episodes. On the fourth day treatment with practolol, $400 \mathrm{mg}$ daily, was begun, which suppressed anginal pain.

The patient was discharged after 15 days, and was put on the waiting list for a coronary arteriography. But after a few days at home, without practolol, he died suddenly, probably from ventricular fibrillation.

\section{Conclusions}

In a group of 7 patients in hospital between 1969 and 197I with clinical evidence of Prinzmetal's angina, 2 patients developed ventricular fibrillation; both were defibrillated electrically. In one of these patients, coronary arteriography and subsequent

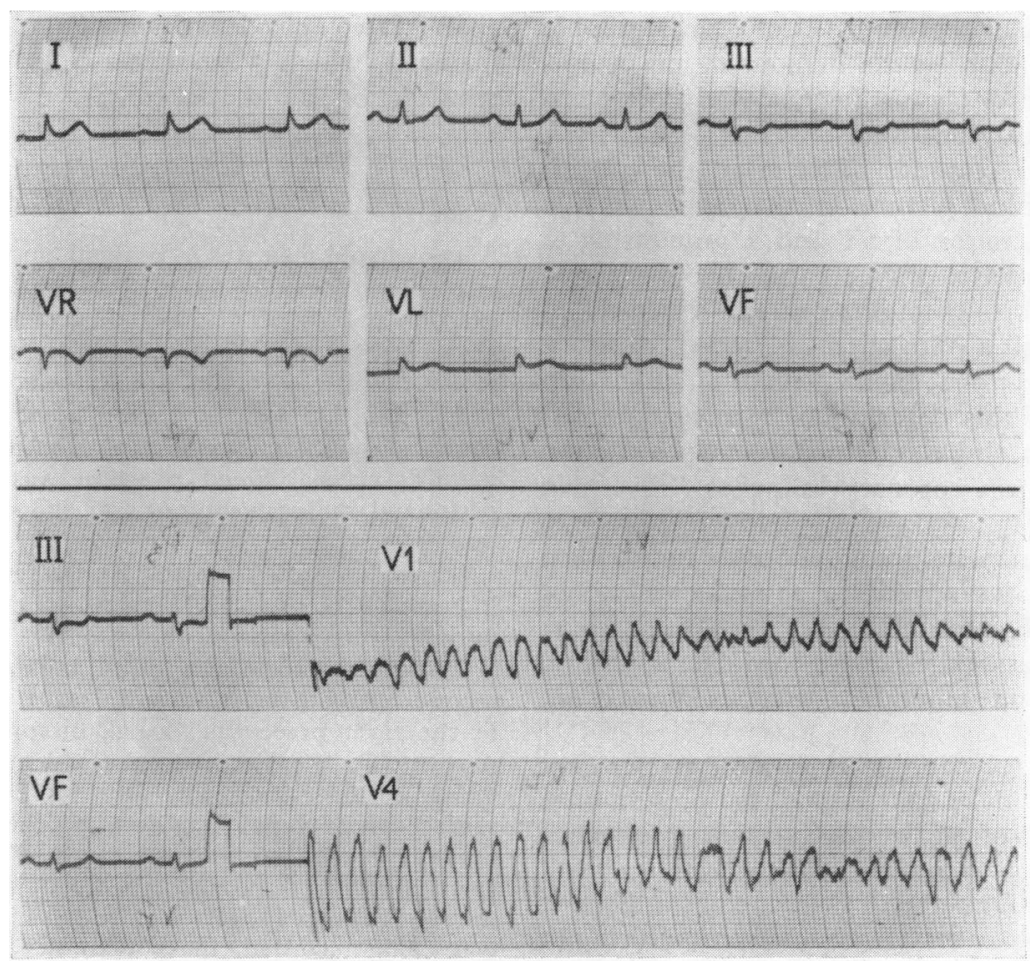

FIG. I Case 2, episode of ventricular fibrillation. 


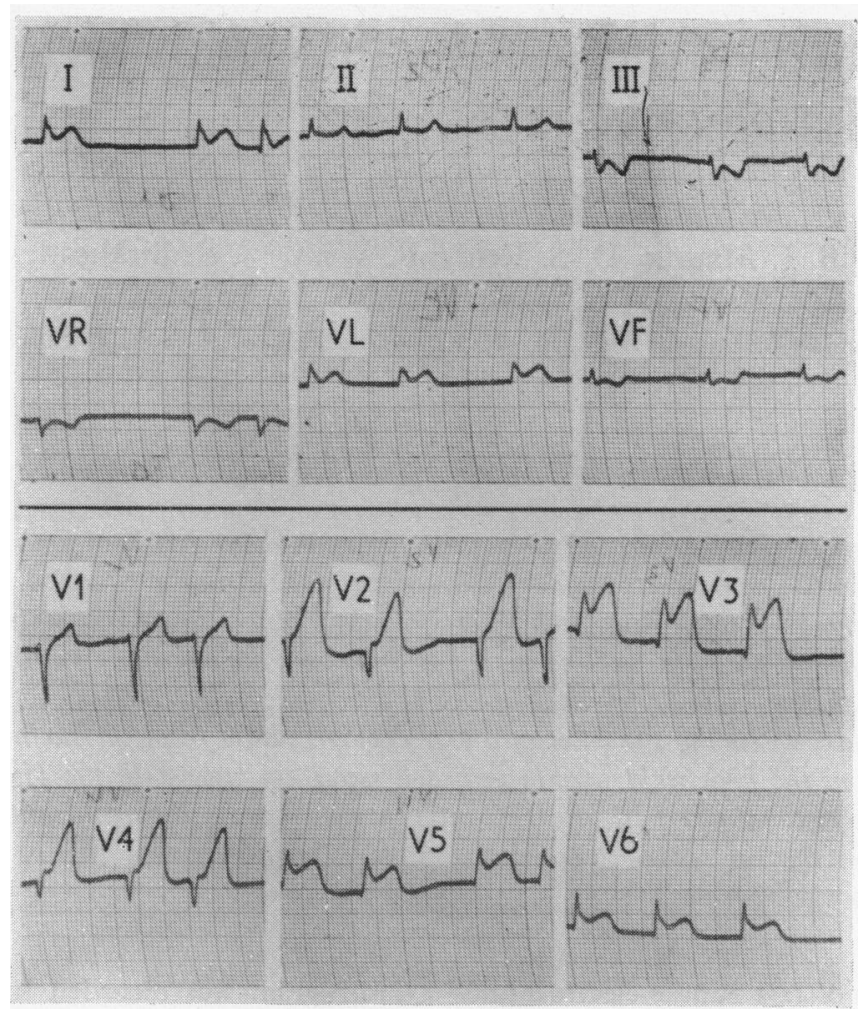

FI . 2 Case 2, Prinzmetal's angina with atrial fibrillation.

operation confirmed the existence of a proximal stenosis of the anterior descending coronary.

A number of clinical and therapeutic considerations emerge from these observations:

Prinzmetal's angina may often be accompanied by episodes of ventricular arrhythmia (extrasystole and ventricular fibrillation). Consequently, patients with variant angina should be admitted to a heart monitoring unit.

Beta-adrenergic blocking agents appear to be therapeutically effective, anginal pain and arrhythmia being controlled in both our cases with practolol.

Aortocoronary venous bypass apparently represents the correct surgical procedure for these patients.

\section{References}

Dorra, M., Waynberger, M., Nezry, R., and Slama, R. (I968). A propos d'une observation d'angor dit de Prinzmetal à forme syncopale. Etude coronarographique. Archives des Maladies du Coeur et des Vaisseaux, 61, 1043.
Guazzi, M., Fiorentini, C., Polese, A., and Magrini, F. (1970). Continuous electrocardiographic recording in Prinzmetal's variant angina pectoris. A report of four cases. British Heart fournal, 32, 61 I.

Meriel, P., Galinier, F., Bounhoure, J. P., Mignon, J. P., and Salvador, M. (1966). Onde monophasique et tachycardie ventriculaire dans l'angor spontané de type Prinzmetal. Archives des Maladies du Coeur et des Vaisseaux, 59, 460.

Peretz, D. I. (I96I). Variant angina pectoris of Prinzmetal. Canadian Medical Association fournal, 85, 1101.

Prinzmetal, M., Kennamer, R., Merliss, R., Wada, T., and Bor, N. (1959). Angina pectoris I. A variant form of angina pectoris. American fournal of Medicine, 27, 375.

Raynaud, R., Brochier, M., Morand, P., Fauchier, J. P., Raynaud, P., and Chatelain, B. (1969). Une forme clinique de l'angine de poitrine: l'angor de Prinzmetal. Semaine des Hôpitaux de Paris, 45, 2662.

Silverman, M. E., and Flamm, M. D. (I97I). Variant angina pectoris. Anatomic findings and prognostic implications. Annals of Internal Medicine, 75, 339.

Requests for reprints to Dr. G. F. Levi, Spedali Civili di Brescia, Medicina Generale IVa Divisione-Gussago, 25064 Gussago, Brescia, Italy. 